Agro-Science Journal of Tropical Agriculture, Food, Environment and Extension Volume 13 Number 1 January 2014 pp. 1 - 7

ISSNIII9=7455

\title{
AWARENESS OF CLIMATE CHANGE AND INDIGENOUS COPING STRATEGIES OF WOMEN CROP FARMERS IN KOGI STATE, NIGERIA
}

\author{
Daudu, A.K." Adesiji, G.B., Matanmi, B.M., Olorunfemi, O.D. and Agbana, O. \\ Department of Agricultural Extension and Rural Development, \\ University of Ilorin, Ilorin, Nigeria \\ *Corresponding author email: kamal_4real@yahoo.com
}

\begin{abstract}
The study assessed the awareness and indigenous coping mechanism employed by women crop farmers to cope with climate change in Kogi State, Nigeria. Respondents' socioeconomic characteristic, level of awareness about climate change, and indigenous coping strategies to climate change as well as activities of women crop farmers that contributed to climate change were investigated. Four-stage sampling techniques were employed in selecting 200 women crop farmers used in the study. Analytical tools used include frequency counts, Percentage and Pearson Product moment correlation. Findings showed that crop rotation practices, planting of early maturing seed, reduced use of chemical fertilizers and changing of crop varieties as indicated by more than $60 \%$ were the indigenous coping strategies commonly used among the respondents. Also, some of the major activities of respondents that contributed to climate change as indicated by more than $50 \%$ of the respondents includes: bush burning, deforestation, continuous cropping, and complete tillage. Person Product Moment Correlation analysis result revealed that; educational level and farm size have significant $(p<0.05)$ influence on the level of awareness and sources of information. It was concluded that greater number of women crop farmers in the study area use indigenous coping method to mitigate the effect of climate change. Therefore, future policy should focus on awareness creation on climate change through different sources such as mass media and extension, encouraging informal social net-works, facilitating the availability of credit, enhancing research on the use of new crop varieties that are more tolerant to changing climate.
\end{abstract}

Keywords: Awareness, climate change, indigenous, coping strategies, women farmers.

\section{INTRODUCTION}

Climate change is today's most debated environmental issue. It is an important issue because it can affect all facet of the society and the livelihood of people especially the rural farmers. The IPCC (Intergovernmental panel on climate change) definition of climate change is a change in climate that can be identified and persists for a decade or longer. The united nations frame work convention on climate change (UNFCCC) on the other hand refers to a change in the climate that is additional to natural variations and directly or indirectly can be connected to human activities and observed over a longer time period. These are the two widely used definitions (IPCC, 2007).

Research findings have shown that agriculture in developing countries is currently being affected by climate change (FAO, 2007; IFPRI, 2009). Agricultural based livelihood systems that are already vulnerable to climate change risk increased crop failure and destruction of productive assets. The effect of climate change is currently being felt in rural areas (LEISA, 2008.) The rain-fed farming systems and forest-based systems are currently experiencing the effect of climate change. FAO, (2008) states that rural people inhabiting the flood plains and low- lying delta, reaions mountains, drylands as well as the arctic are more at risk.

The small-scale farmers still suffers most because of their dependence on rain-fed agriculture and lack of capacity to diversify. Carter (1997) pointed out that farmers react to climate change through adaptation. In an analysis of adaptation to climate change in the drought prone areas of Bangladesh, Selvaraju et al. (2006) found that the main adaptation strategies practiced by small-scale farmers were in the form of modification of agronomic practices and in the choice of crop varieties that tolerate the new regime.

Most studies assessing the potential effects of climate change on African agriculture are regional or national and yet adaptation is place-based and needs the use of place-specific strategies (Fischer et al., 2002; Hassan and Nhemachena, 2008; Kurukulasuriya and Mendelsohn, 2008; Lobell et al., 2008; Seo et al., 2009; Deressa et al., 2011). There is also limited knowledge on whether farmers perceive climate change and how they are responding 
to the effects of a changing climate. It is also important to note that local perceptions cannot be estimated by models and the need to document how the lives of the local people are affected by the recent changes in climate.

However, the level of awareness of climate change impact is very low. The capacity of farmers to adapt to climate change can be significantly influenced by the level of awareness about climate change in their communities. In this regard, Tol (1998) suggested that awareness about climate change has great capacity to drive farmers to improvise local technologies to aid adaptation. According to the UNDP report (2010), the level of awareness about climate change is rather low in Nigeria, and it is likely to continue if no intervention measures are taken. The survey noted that the awareness of climate change was highest at the federal level. This dropped sharply at the state and local government levels, where real action is needed. Over time, farmers have adjusted agricultural systems and practices to meet changing economic and physical conditions by adopting new technologies, changing crop mixtures and institutional arrangements. Such flexibility suggests a human potential to adapt to climate change (CAST, 1992; Rosenberg, 1992). Wisner et al (2004) reported that the vulnerability of agriculture is not determined by the nature and magnitude of environmental stress like climate change perse, but by the combination of the societal capacity to cope with and/or recover from environmental change.

Coping strategy can be viewed as reducing the severity of many impacts when adverse conditions prevail. That is, coping strategies reduce the level of damage that might have otherwise occurred. The success of coping strategy or adaptation depends critically on the availability of necessary resources, not only financial and natural resources, but also knowledge, technical capability, and institutional resources (PCGCC, 2004). In addition, many social, economic, technological and environmental trends also critically shape the ability of farmers to perceive and adapt to climate change. Knowledge of the adaptation methods and factors affecting farmers' choices enhance efforts directed towards tackling the challenges that climate change is imposing on farmers (Deressa et al., 2009). Thus, for many poor countries that are highly vulnerable, understanding farmers' response to climate change is crucial in designing appropriate coping strategies (Mohmud et al., 2008). The vulnerability of poor countries is due to weak institutional capacity, limited engagement in environmental and adaptation issues, and a lack of validation of local knowledge (Adams et al., 1998).

Aymone (2009) argue that farmers who have access to extension services are more likely to be aware of changing climatic conditions and to have knowledge of the various management practices that they can use to adapt to changes in climatic conditions. Information on temperature and rainfall also has a significant and positive impact on the likelihood of using different crop varieties. Having access to farmer-to-farmer extension increases the likelihood of using different crop varieties and planting trees (Deressa et al., 2009). Evidence abounds (Katz and Brown, 1992) that farmers can adapt to climate change by changing their agricultural practices, which may include planting tolerant crop varieties or changing husbandry practices. Adaptation may also involve blending scientific practices with local/traditional knowledge. It is expected that crop productivity will be altered due to weather events and changes in the pattern of pests and diseases (Aydinal and Cresser, 2008).

A better understanding of the local dimensions of climate change is essential to develop appropriate coping mechanism that will mitigate adverse consequences of climatic change impact. The knowledge of the coping choices and factors affecting the adaptation methods to climate change enhance policy towards tackling the challenge that climate change is imposing on farm households having little adaptation capacities.

The main objective of this study was to analyze the awareness of climate change and indigenous coping strategies among women crop farmers in Kogi State, Nigeria. It is hypothesized that the socio-economic characteristics of the respondents do not influence their level of awareness about climate.

The specific objectives of this study were to:

(1) Identify the socio-economic characteristics of the respondents;

(2) ascertained the awareness of climate change among respondents in the study area;

(3) identify the activities of farmers that contributed to climate change in the area;

(4) determine the indigenous coping mechanism employed by women crop farmers to ameliorate the effect of climate change

\section{MATERIALS AND METHODS}

The study was conducted in Kogi State of Nigeria. The State is in the central region of Nigeria. It lies within $7^{0} 30 \mathrm{~N}$ and $6^{0} 42 \mathrm{E}$. It has a land area of 29,833 square kilometres, 709,000 farming families and a total population of $3,278,495$ comprising 1,691,737males and 1,586,758 females (NPC, 2006). The study area is basically agrarians. About $70 \%$ of the population resides in rural areas with $80 \%$ being farmers out of which $50 \%$ of farmers are women (NBS, 2008). The population of the study comprised all women crop farmers in Kogi State. Agriculturally, Kogi State is divided in to four Agricultural Development Project (ADP) zones. Four-stage sampling techniques were used in selecting respondents for the study. 
Both primary and secondary data sources were used. Primary data were collected from sample households and focus group discussions and semistructured questionnaire through interviewing method. Secondary data sources include internet, agricultural journals, Kogi State Agricultural Development Project and Ministry of Agriculture and Natural Resources. Descriptive and inferential statistics were used to analyze the data. Descriptive statistical tools (frequency and percentages) were used to categorize the respondents based on socioeconomic characteristics; awareness to climate change, indigenous coping strategies used by women farmers and activities women crop farmers that contributed to climate change. The inferential statistical tool, mainly the Pearson Product Moment Correlation (PPMC) was used to establish the relationship between some socio-economic characteristics and the awareness about climate change among women farmers.

\section{RESULTS AND DISCUSSION}

Result presented in Table 1 revealed that about $(40.2 \%)$ of the respondents were within the age of 41 - 49 years. This shows that majority of the respondents were within the active age. While $35.5 \%$ are young $(\leq 40)$ and $23.4 \%$ are old women crop farmers who are greater than or equal to fifty years of age. They were aged about 48 years on the average with the oldest being 65 years and the youngest being 25 years. Age of the household head, which represents experience, affected coping mechanism to climate change positively. Experience in farming increased the probability of uptake of adaptation measures to climate change (Maddison, 2006; Nhemachena and Hassan, 2008; Aymone, 2009; Deressa et al., 2009).

Marital status revealed, majority $(75.7 \%)$ of the respondents were married, and this may be attributed to the belief that getting married will help to reduce the cost of hired labour on the farm as family members will assist in some farm. Work . Marriage is also regarded as mark of honour and prestige which is held in high esteem in the study area. $11.9 \%$ of the respondents were single while widowed and divorced constituted $10.8 \%$ and $1.6 \%$ of the respondent, respectively. Educational attainment revealed that only $35.6 \%$ of the respondents had no formal education while the remaining $64.4 \%$ had one form of formal education or another. This is an indication that level of formal education among women crop farmers in the study area is relatively low. Educated and experienced farmers are expected to have more knowledge and information about climate change and agronomic practices that they can rely. Maddison (2006), found that farmers' awareness of changes in climate attributes (temperature and precipitation) is important for adaptation decision making. Deressa et al. (2009) also found that education was significantly increases soil conservation and changing planting dates as an adaptation method. Also, on the religion of the respondents, the table indicated that $53 \%$ were Christians and 47\% were Muslims.

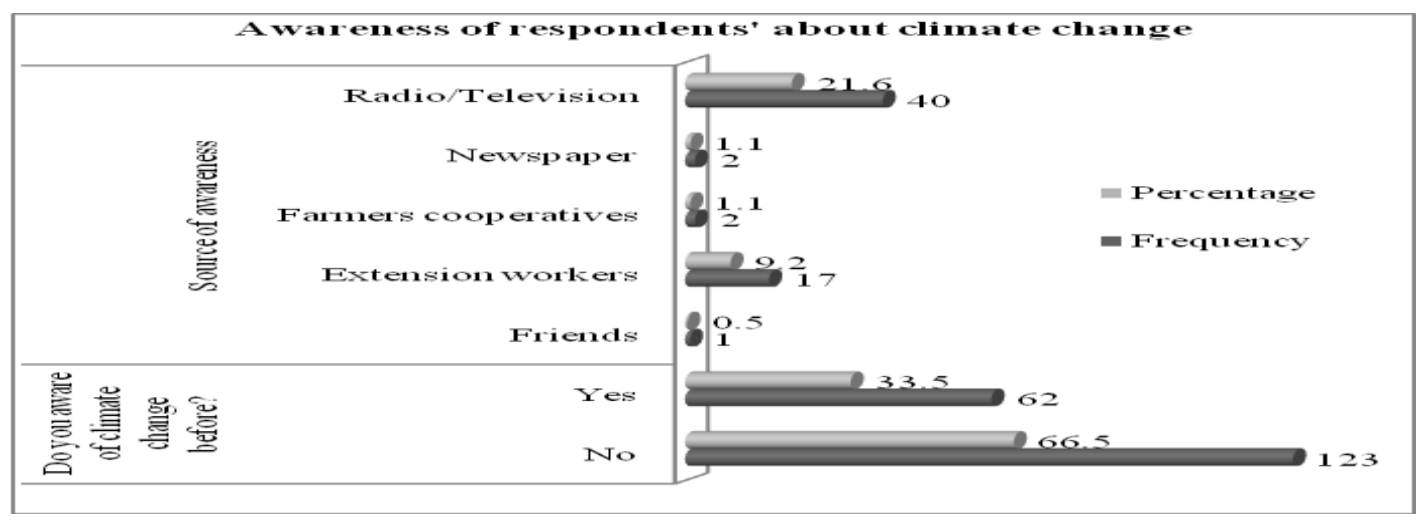

Figure 1: Awareness of respondents' about climate change Source: Field survey data, 2012 
Table 1: Socioeconomic Characteristics of women crop farmers

\begin{tabular}{lcc} 
Variable & Frequency & Percentage \\
\hline Age (years) & 45 & 35.5 \\
$\leq 40$ & 74 & 40.2 \\
$41-49$ & 66 & 24.3 \\
$\geq 50$ & & \\
Marital Status & 22 & 11.9 \\
Single & 140 & 75.7 \\
Married & 20 & 10.8 \\
Widowed & 3 & 1.6 \\
Divorced & & \\
Education & 66 & 35 \\
No formal Education & 17 & 9.2 \\
Quranic Education & 2 & 1.1 \\
Adult Education & 52 & 28.1 \\
Primary Education & 44 & 23.8 \\
Secondary Education & 4 & 2.2 \\
Tertiary Education & & \\
Religion & 98 & 53 \\
Christianity & 87 & 47 \\
Islam & & \\
Farming experience & 18 & 9.7 \\
$1-5$ years & 32 & 17.3 \\
$6-10$ years & 83 & 44.9 \\
$11-15$ years & 38 & 20.5 \\
$16-20$ years & 14 & 7.6 \\
Above 20 years & & \\
Farm size (ha) & 46 & 24.9 \\
< 1 & 121 & 65.4 \\
4-5 & 12 & 6.5 \\
$>5$ & 6 & 3.2 \\
Extension visit & & \\
No & 108 & 58.4 \\
Yes & & 41.6 \\
\hline Source: Field survey, 2012 & &
\end{tabular}

However, farming experience indicates that, most $(44.9 \%)$ of respondents had farming experience between 11 - 15 years, $20.5 \%$ had farming experience between $16-20$ years, and only $9.7 \%$ had between $1-5$ years of farming experience. This means that majority of farmers are likely to be conversant with issues that affect high yield of crops, most especially climate change. Hassan and Nhemachena (2008) noted that it is farming experience that matters more than merely the age of the farmer when it comes to adaptation to climate change. Study by Hassan and Nhemachena (2007) who found that the farmer's experience increases the probability of uptake of all adaptation options. Also, the socio-economic profile (Table 1) further reveals that majority $(65.4 \%)$ of the respondents operated 2 to 3 ha of farmland, between $4-5$ hectares were operated by $6.5 \%, 3.2 \%$ of the respondents operate above 5 hectares while $24.9 \%$ operate $\leq 1$ hectare of farmlands. This finding indicates that the majority of respondents are small-scale farmers. Small-scale farmers operate at subsistent level, making them vulnerable and less able to cope with the consequences of climate change, as indicated by Oyekale (2009).

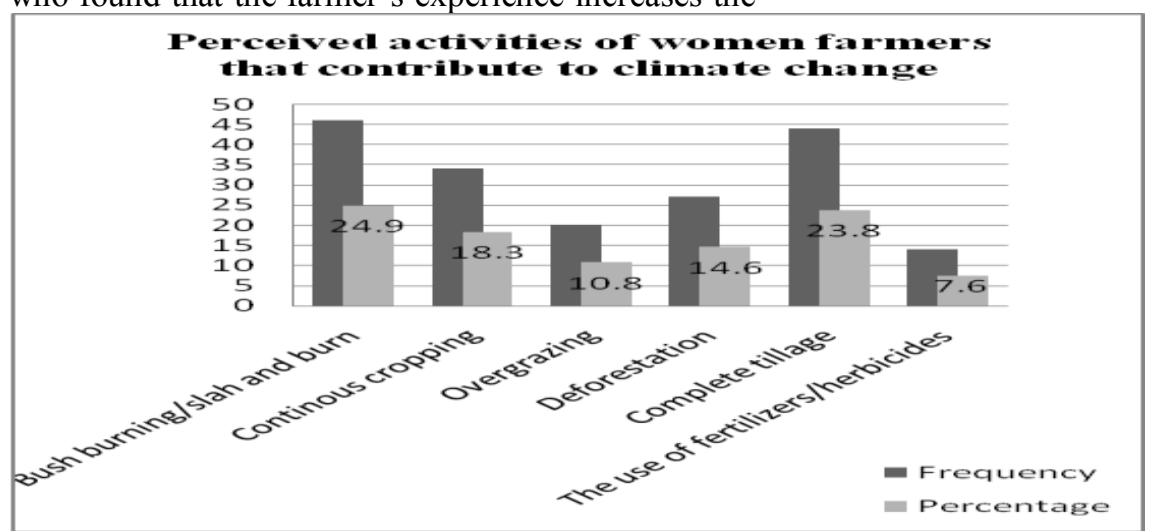

Figure 2: Activities of women crop farmers that contributed to climate change Source: Field survey data, 2012 
Table 2: Indigenous coping strategies employed by women crop farmers

\begin{tabular}{lll|}
\hline Indigenous coping strategies employed by women farmers & Freq & \% \\
\hline Change of tillage practices & 138 & 75.6 \\
Crop rotation & 143 & 77.3 \\
Change of crop varieties & 111 & 60 \\
Mulching & 134 & 72.4 \\
Reduced use of chemical fertilizer & 127 & 68.6 \\
Planting early maturing seed & 169 & 91.4 \\
Altering plant schedule & 155 & 83.8 \\
Change of tillage practices & 138 & 75.6 \\
\hline
\end{tabular}

Source: Field survey, 2012

*Multiple responses resulted in a total percentage $>100 \%$

Table 3: Relationship between selected socio-economic and the awareness of women crop farmers about climate change

\begin{tabular}{lll|}
\hline & Correlation & Decision \\
\hline $\begin{array}{l}\text { Age } \\
\text { Swareness }\end{array}$ & $0.008(0.913)$ & Not significant \\
Education & $-0.015(0.845)$ & Not significant \\
Awareness & & \\
Source of awareness & $0.644^{* *(0.000)}$ & Significant \\
Farm size & $0.605^{* *}(0.000)$ & Significant \\
Awareness & & \\
Source of awareness & $0.190^{* *}(0.010)$ & Significant \\
\hline
\end{tabular}

**Correlation is significant at 0.01 level $(2$ - tailed).

Source: Data analysis, 2012

Lastly, extension visits afford the farmers the opportunity to learn improved technologies and how to acquire the needed inputs and services. The distribution of respondents by extension visits is also presented in Table 1. The distribution reveals that majority of the respondents (about 58.4\%) had no contact with extension agents, while only about $41.6 \%$ were visited by extension agents. This could affect climate change adaptation among farmers, since their understanding of climatic change depends only on their previous experience. Better access to extension services seems to have a strong positive influence on the probability of choosing in adaptation measures (Aymone, 2009; Deressa et al., 2009). Aymone (2009) argue that farmers who have access to extension services are more likely to be aware of changing climatic conditions and to have knowledge of the various management practices that they can use to adapt to changes in climatic conditions. Information on temperature and rainfall also has a significant and positive impact on the likelihood of using different crop varieties. Having access to farmer-to-farmer extension increases the likelihood of using different crop varieties and planting trees (Deressa et al., 2009).

Figure 1, sought the level of awareness about climate change among the respondents. Results of the level of awareness of climate change among the respondents revealed that the majority $(66.5 \%)$ of respondents were not aware of the changing climate while only $33.5 \%$ of respondents revealed that they were aware of climate change. This suggests a low level of awareness of issues about climate change among respondents. This situation corroborates with finding of Maddison (2006) that educated farmers have more knowledge and information about climate change. Of that figure, out of $33.5 \%$ of respondents who indicated they were aware about of issues climate change $21.6 \%$ got their information about climate change from radio/television while $9.2 \%$ from extension workers. This underscores the importance of interpersonal communication in creating awareness. According to Hassan and Nhemachena (2007), access to information about climate change forecasting, adaptation options and other agriculture activities remain important factors determining use of various coping strategies.

The perception of the respondents as to the activities of women crop farmers that contributed to climate change (Figure 2) shows that majority $(24.9 \%)$ of the respondents perceived climate change as being caused by bush burning, $23.8 \%$ caused by complete tillage operation, while $18 \%$ of the respondents agreed that it was caused by continuous cropping of farmland and $14.6 \%$ caused by 
deforestation. This was followed by complete tillage operation, as claimed by $23.8 \%$ of the respondents, while $18.3 \%$ of the respondents claimed that continuous cropping activities are responsible for climate change. Other activities that contribute to climate change are deforestation, overgrazing and the use of fertilizers/herbicides as reported by $14.6,10.8$ and $7.6 \%$ of the respondents, respectively.

Indigenous coping mechanism measures embarked upon by the respondents to minimize the effect of climate change in the area is presented in Figure 3. The distribution shows that about $91.4 \%$ of the respondents use early maturing seed, while about $77.3 \%$ practiced crop rotation. Also, about $75.6 \%$ of the respondents' change their tillage practice, ii about $60.0 \%$ use different crop variety, and $72.4 \%$ use mulching to ameliorate climate change. Bradshaw et al. 2004; Kurukulasuriya and Mendelsohn 2006; and Nhemachena and Hassan, 2007 discovered that the use of new crop varieties and livestock species that are more suited to drier conditions, irrigation, crop diversification, mixed farming and change in planting dates, help in mitigating the effect of climate change. This study has revealed that farmers use different coping strategies to minimize the effect of climate change in the area.

From Table 3, it is evident that only the level of education $(0.644 * *)$ and farm size $(0.190 * *)$ showed a significant relationship with the level of awareness of women crop farmers at 0.01 level of significance. The result further showed that level of education $(0.190 * *)$ showed a positive relationship with source of information while there was an inverse relationship $(-0.196 * *)$ between farm size and source of information on climate change adaptation. This implies that as the farmers' level of education increases their awareness and sources of information improves. On the other hand, as the farm size increases their level of awareness increases but sources of information become poor. Data analysis also revealed that age showed no significant relationship with the level of awareness and sources of information of respondents.

\section{CONCLUSION}

The conclusion drawn from this study is that few of the women farmers were aware of climate related issues. A large number of them that they use indigenous coping mechanisms to combat climate change. The women farmers are making efforts to adapt to climate change planting of early maturing, crops, changing of crop varieties, crop rotation, improved tillage practices and altering of planting date. They however lacked adequate information on how to adapt. The perceived activities contributing to climate change in the area was bush burning, deforestation, continuous cropping and overgrazing of farmland.

\section{RECOMMENDATIONS}

From the foregoing, it is recommended that:

i. There is need to promote women's education, awareness creation and increased access to credit facilities and agricultural inputs as potent tools for climate change adaptation in the study area.

ii. Farmers should adjust planting dates to avoid crop failure due to late onset and early cessation of rains.

Extension service should be strengthened through organizing adult education programmes for farmers to expose them to climate change coping strategies.

\section{REFERENCES}

Adams, R.M., Hurd, B.H., Lenhart, S. and N., Leary, 1998. Effects of global change on agriculture: an interpretative review. Climate Research, 11: 19-30.

Aymone, G. G., 2009. Understanding farmers' perceptions and adaptation to climate change and variability: The case of the Limpopo basin, South Africa. IFPRI Discussion paper 00849, International Food Policy Research Institute: Washington DC.

Deressa Temesgen, R.M., Hassan, C., Ringler, Tekie Alemu and Mahmud Yesuf, 2009.

Determinants of farmers' choice of adaptation methods to climate change in the Nile Basin of Ethiopia. Global Environmental Change, 19: 248-255.

CAST. (1992). Council for agricultural science and technology. Preparing US agriculture for global climate change. Task Force Report, No. 119.

Carter, M.R. (1997). Environment, technology and the social articulation of risk in West African agriculture. Economic Development and Cultural Change, 45: 557-590.

FAO; (2008) Climate change and food security: A Framework Document. Rome Food and Agriculture Organization

Fischer, G., Shah, M., \& van Velthuizen, H. (2002). Climate Change and Agricultural Vulnerability. International Institute for Applied Systems Analysis. Report prepared under UN Institutional Contract Agreement 1113 for World Summit on 
Sustainable Development. Laxenburg, Austria.

Hassan, R., \& Nhemachena, C. (2008). Determinants of African farmers' strategies for adapting to climate change: Multinomial choice analysis. African Journal of Agricultural and Resource Economics, 2 (1): 83-104.

Katz, R.W., Brown, B.G. (1992). Extreme events in changing climate: variability is more important than averages. Climate Change, 21: 289-302.

Kurukulasuriya, P., \& Mendelsohn, R. (2008). How Will Climate Change Shift Agro-

Ecological Zones and Impact African Agriculture? Policy Research Working Paper 4717. Sustainable Rural and Urban Development Team, Development Research Group, The World Bank.

Lobell, D. B., Burke, M. B., Tebaldi, C., Mastrandrea, M. D., Falcon, W. P., \& Naylor, R. L. (2008). Prioritizing climate change adaptation needs for food security in 2030. Science, 319(5863), 607-610. http://dx.doi.org/10.1126/science. 115 2339

LEISA; (2008) Dealing with climate change, Leisa, 24 (4): pp. 9-11.

Mohmud Yesuf, Di Falco,S., Ringler, C., Kohlin,G., 2008. Impact of climate change and adaptation to climate change on food production in low income countries: household survey data evidence from the Nile basin of Ethiopia. IFPRI Discussion paper No.
828. International food policy research institute, Washington, DC.

Oyekale, A.S. (2009). Climatic variability and its impact on agricultural income and

households' welfare in southern and northern Nigeria. Electronic Journal of Environmental, Agricultural and Food Chemistry, 8(1): 13-34.

PCGCC (Pew Center on Global Climate Change), 2004. Coping with global climate change:

The role of adaptation in the United States. PCGCC: Arlington.

Rosenberg, N.J. (1992). Adaptation of agriculture to climate change. Climate Change, 21:385- 405.

Selvaraju, R., Subbiah, A.R., Baas, S., Juergens, I. (2006). Livelihood adaptation to climate variability and change in drought-prone areas of Bangladesh. Food and Agriculture Organization (FAO).

Seo N. S., Mendelsohn, R., Dinar, A., Hassan, R., \& Kurukulasuriya, P. (2009). A Ricardian Analysis of the Distribution of Climate Change Impacts on Agriculture across Agro-Ecological Zones in Africa. Environment and Resource Economics, 43: 313-332. http://dx.doi.org/10.1007/s10640-0099270-z

Tol, R.S. (1998). Adaptation to climate change in the context of sustainable development and equity. Global Environmental Change, 8(2): 109123. 